\title{
Providers' Experiences with Delivering School-Based Targeted Prevention for Adolescents with Anxiety Symptoms: A Qualitative Study
}

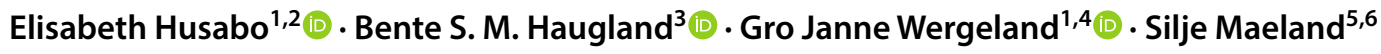

Published online: 21 July 2020

(c) The Author(s) 2020

\begin{abstract}
The school setting is important for delivering targeted prevention to adolescents with anxiety. However, schools may not have available providers with training or experience in delivering evidence-based interventions, e.g., school psychologists. Training providers available in the schools, e.g., school nurses, is important. Further, to investigate their experiences in delivering targeted prevention to adolescents with anxiety could help understand factors promoting implementation success. A qualitative study including focus groups with providers of school-based targeted prevention cognitive-behavioral therapy for anxiety in adolescents was conducted. Focus group interviews were audiotaped and transcribed verbatim. Systematic Text Condensation, a method for thematic cross-case analysis was used. The Active Implementation Framework (AIF) was used to contextualize the results. Seventeen providers participated in the study. They reported several facilitators contributing to successful implementation: Their feeling of competence in delivering the interventions were built through skills-based training, supervision, and collegial support. Conducting initial assessment of each adolescent helped the providers individualize the interventions. Seeing positive outcomes in adolescents gave the providers motivation to continue implementation. Further, collaborating with teachers facilitated both recruitment of adolescents and administering group sessions. Minimal leadership-oriented factors were reported. Overall, the findings correspond to some of the drivers in AIF. This study offers providers' perspectives on implementation of targeted prevention for anxiety in the school setting. Our results show that providers experience mastery in delivery when receiving support, training, and supervision. This seems to be essential facilitators for implementing much needed targeted prevention for youth with anxiety.
\end{abstract}

Keywords Implementation · Prevention · School-based C CBT · Focus group · Adolescents

Elisabeth Husabo

elisabeth@husabo.no

1 Division of Psychiatry, Department of Child and Adolescent Psychiatry, Haukeland University Hospital, Bergen, Norway

2 RKBU West, NORCE Norwegian Research Center, Bergen, Norway

3 Department of Clinical Psychology, University of Bergen, Bergen, Norway

4 Department of Clinical Medicine, University of Bergen, Bergen, Norway

5 Research Unit for General Practice, NORCE Norwegian Research Center, Bergen, Norway

6 Department of Global Public Health and Primary Care, University of Bergen, Bergen, Norway
The school setting may be optimal for delivering prevention to adolescents with elevated anxiety symptoms, when provided at school and during school hours (Werner-Seidler, Perry, Calear, Newby, \& Christensen, 2017; Lyon \& Bruns, 2019). Anxiety symptoms are prevalent among adolescents (Balazs et al., 2013), and may lead to impairment in school performance (Mazzone et al., 2007), psychosocial functioning (Angold, Costello, Farmer, Burns, \& Erkanli, 1999), as well as increased likelihood of later anxiety disorders or other psychopathology (Pine, 2007; Wittchen, Beesdo, Bittner \& Goodwin, 2003). Further, according to school nurses, anxiety is the most prevalent mental health issue among adolescents seeking help from school nurses (Muggeo \& Ginsburg, 2019). However, providers available to deliver mental health interventions in schools (e.g., school nurses, school counselors, social workers, hereafter collectively referred to as school providers) usually do not 
have training or experience in delivering evidence-based interventions (Stephan \& Connors, 2013; Muggeo, Stewart, Drake, \& Ginsburg, 2017). Thus, training school providers in delivering evidence-based targeted prevention for adolescents with anxiety may be beneficial in order to reduce anxiety symptoms, reduce impairment and hinder or postpone onset of anxiety disorders (Haugland et al., 2020). Such efforts are also essential because only a limited number of adolescents with anxiety disorders are identified and referred for treatment in specialized mental health settings (e.g., community mental health clinics; Merikangas et al., 2011; Waite \& Creswell, 2014). Yet, school-based mental health interventions are generally not implemented, or often implemented unsuccessfully (Fixsen, Naoom, Blasé, Friedman, \& Wallace, 2005; Forman \& Barakat, 2011). Studying what facilitates successful implementation of targeted prevention for mental health problems in schools is therefore of great importance.

Mental health interventions in the school setting can be implemented via a multi-tiered system of support (MTSS). Based on a public health model of prevention, MTSS is organized as a continuum of three levels (universal, targeted, and indicated; Jones, West, \& Suveg, 2019; Fabiano $\&$ Evans, 2018). The universal level is provided to all adolescents, the targeted level is provided to youth at risk and the indicated level is provided to youth with severe problems. School health services are typically organized with district-employed school nurses, social workers, or school counselors preforming tasks such as annual physical examination and supportive care for mental health problems on an as-needed basis (Parhiala et al., 2019; Foster, Rollefson, Hoagwood, Crowe, \& Saka, 2009; Norwegian Directorate of Health 2019). Evidence-based targeted prevention for anxiety exist that could be delivered by school providers (Werner-Seidler, Perry, Calear, Newby, \& Christensen, 2017; Fazel, Hoagwood, Stephan, \& Ford, 2014; Masia Warner et al., 2016). However, available school providers infrequently deliver evidence-based mental health interventions (Muggeo \& Ginsburg, 2019; Evans, Koch, Brady, Meszaros, \& Sadler, 2013) and report low level of ease in providing such interventions (Stephan \& Connors, 2013). Further, little is known about facilitators needed to succeed in implementation of such interventions.

\section{Literature Review}

In a systematic review of implementation of evidencebased practices for youth mental health, only four schoolbased studies were identified, and none of these were interventions for emotional problems (e.g., anxiety; Novins, Green, Legha, \& Aarons, 2013). Developers of evidence-based school interventions have reported several facilitators in a study of their experiences with implementation (Forman, Olin, Hoagwood, Crowe, \& Saka, 2008). The interventions they were developers of were predominantly cognitive-behavioral therapy (CBT) targeting a range of problems and/or skills, e.g., substance abuse, poor school climate, externalizing behavior, and trauma (Forman, Olin, Hoagwood, Crowe, \& Saka, 2008). Important facilitators to implementation and sustainability were support from school leadership and teachers, stable funding, high-quality training, supervision, and alignment with school goals and programs (Forman, Olin, Hoagwood, Crowe, \& Saka, 2008). These findings are supported in a study of school-based CBT providers reporting a need for more internal support, and the importance of supervision (Ringle et al., 2015).

In a study of school providers delivering CBT for anxiety disorders, positive provider attitudes to evidence-based practices were related to better implementation, while other provider characteristics (e.g., change in skill and knowledge after training) and organizational-level variables (e.g., organizational readiness for change) did not affect implementation (Beidas et al., 2012). However, successful implementation has been associated with greater organizational structure and administrative implementation support in a study of schoolbased CBT for trauma (Langley, Nadeem, Kataoka, Stein, \& Jaycox, 2010). Another study of providers' experiences implementing a school-based intervention targeting anxiety and depression symptoms in children (8-12 years), identified factors such as limited time, heavy workload, lack of supportive leadership, and lack of cooperation with teachers and principals as barriers to implementation (Rasmussen et al., 2019). The providers were health care and child-care professionals employed by different municipal services, e.g., community mental health clinics, health care services, and educational and psychological services (Rasmussen et al., 2019). Importantly, the same barriers were reported from providers from different municipal services (Rasmussen et al., 2019).

The increased focus on mental health interventions in schools is good (Murphy, Abel, Hoover, Jellinek, \& Fazel, 2017). However, there is a challenge to fit these into the school setting, with the majority of anxiety interventions comprising 8-12 sessions (Werner-Seidler, Perry, Calear, Newby, \& Christensen, 2017). Competing academic demands will often be prioritized over extra-curricular programs targeting anxiety (Forman \& Barakat, 2011). Thus, shorter interventions may be easier to fit within the school setting. The fit of an intervention with the setting is an important factor for sustainability (Lyon \& Koerner, 2016; Forman, Olin, Hoagwood, Crowe, \& Saka, 2008). Examining providers' experiences with implementing shorter interventions for adolescents with anxiety could therefore 
yield knowledge of different facilitators than what have been found in previous studies.

\section{Theoretical Framework}

Implementation involves deliberate actions with the goal of using an evidence-based intervention in a specific context (Fixsen, Naoom, Blasé, Friedman, \& Wallace, 2005). Implementation is a complex process, as it may be impacted by numerous factors related to the intervention, the providers delivering the intervention, the clients receiving it and the context the intervention is used in (Bertram, Blase, and Fixsen, 2015). Evidence-based interventions may become ineffective and unsustainable if not enough attention is given to important factors related to the implementation process (Ogden et al., 2012; Bertram, Blase, \& Fixsen, 2015).

Factors or drivers potentially influencing the success of implementation of an intervention, i.e., competency, organization, and leadership, are described in the Active Implementation Framework (AIF; Blase, van Dyke, Fixsen, \& Bailey, 2012; Fixsen, Blase, Naoom, \& Wallace, 2009; Bertram, Blase, \& Fixsen, 2015; Fixsen, Naoom, Blasé, Friedman, \& Wallace, 2005). This framework is based on similarities between successful implementation efforts, identified in a broad literature review and synthesizing of implementation literature across several human services domains (Fixsen, Naoom, Blasé, Friedman, $\&$ Wallace, 2005). The drivers presented in the framework have different goals but are integrated and mutually important to reach the overall aim of implementation (Bertram, Blase, \& Fixsen, 2015). The competency drivers (i.e., selection, training, and supervision of providers) are mechanisms to develop and improve the providers' ability to deliver the intervention effectively and according to the intention of the developers (Blase, van Dyke, Fixsen $\&$ Bailey, 2012). The organization drivers (i.e., systems intervention, facilitative administration, decision support data system) are mechanisms focused on enabling a hospitable organization for the intervention to be delivered (Blase, van Dyke, Fixsen, \& Bailey, 2012). The goal of the leadership drivers (i.e., supportive and adaptive leadership) is to enable delivery in the specific context and facilities, and meeting different emerging challenges with appropriate strategies (Blase, van Dyke, Fixsen, \& Bailey, 2012). The components of the drivers may function in a compensatory manner, i.e., a weakness in one component may be compensated for by a strength in another component (Fixsen, Naoom, Blasé, Friedman, \& Wallace, 2005; Blase, van Dyke, Fixsen, \& Bailey, 2012).

According to AIF, successful implementation of an intervention requires consistent efforts by involved stakeholders (Bertram, Blase, \& Fixsen, 2015). In a school context, stakeholders may be teachers, providers, and leaders (Fixsen, Blase, Metz, \& Van Dyke, 2015a; Blase, van Dyke, Fixsen, \& Bailey, 2012). Efforts needed for implementation may involve leaders and administrative staff allocating resources so that school providers who wish to help adolescents with anxiety, get the opportunity to learn to use the intervention and deliver it with fidelity to adolescents in need (Forman, Ward, \& Fixsen, 2017; Fixsen, Blase, Metz, \& Van Dyke, 2015a). Further, teachers may have to allow students to prioritize participation in anxiety interventions above attending school lectures. These examples express how the implementation drivers together represent the capacity to produce desired outcomes of an evidence-based intervention by adjusting the host organization (Bertram, Blase, \& Fixsen, 2015; Blase, van Dyke, Fixsen, \& Bailey, 2012). By identifying drivers and the relationship between them, AIF may help in planning and understanding implementation (Fixsen, Blase, Naoom, \& Duda, 2015b; Nilsen, 2015). Further, to evaluate specific implementation efforts, such as anxiety interventions in schools, it is important to expand the knowledge and identify facilitators specific to this context. This could further support sustainability and validate theory.

Considering the unmet needs of youth with anxiety (Chavira, Stein, Bailey, \& Stein, 2004; Essau, 2005) and the potential benefits of school-based interventions (Werner-Seidler, Perry, Calear, Newby, \& Christensen, 2017), we need to examine the perspectives of providers who have implemented school-based interventions. Doing this in relation to positive youth outcomes may be important to understand facilitators to implementation success. The present study examines providers' perspectives on administering CBT in a randomized controlled trial (RCT) of school-based targeted prevention for anxiety in adolescents (Haugland et al., 2020).

\section{The Aim of the Study}

The aim of the present study was to explore providers' experiences of factors facilitating successful implementation of targeted prevention for adolescent anxiety symptoms in schools.

\section{Methods}

The present study was part of a multisite RCT, evaluating the effectiveness of two group-based anxiety interventions for adolescents. The interventions were delivered in school facilities, during school hours (ClinicalTrials.gov Identifier: NCT02279251). Methods and main outcomes of the trial are presented in Haugland et al. (2017), (2020). The providers 
administered a total of 52 groups, each with 5-8 adolescents, amounting to 313 adolescents. Video tapes of two sessions from each group were evaluated for treatment integrity (i.e., adherence and competence) and treatment differentiation by independent coders. Treatment integrity was acceptable and differentiation between interventions was excellent (Haugland et al., 2020). Both interventions were found to be effective relative to waitlist control. Outcomes were sustained at 1-year follow-up (Haugland et al., 2020).

\section{Design}

A qualitative focus group study was conducted, aiming to identify factors facilitating successful implementation. Focus group interviews were chosen to benefit from the communicative interaction where participants share their relevant perspectives, building upon each other's comments (Malterud, 2012a; Morgan, 1997). Further, when participants are in a permissive environment among others who have similar experiences, they may more easily express both negative and positive perspectives (Ivanoff \& Hultberg, 2006). Focus groups are considered a method for collecting data that may contribute to understanding of experiences with an intervention (Kitzinger, Pope, \& Mays, 2006; Krueger \& Casey, 2000).

Approval for the present focus group study was obtained from the Data Protection Official for Research, which is the data protection authority in Norway (ID 53716). Principles of the Helsinki Declaration were followed, and written informed consent was obtained from all participants.

\section{Focus Group Participants}

The focus group participants were drawn from the providers in the RCT. There was a total of 32 providers $(M$ age $=43.20$, $\mathrm{SD}=8.09$, range $32-62 ; 93.8 \%$ female) in the RCT. These were mainly school personnel (i.e., school nurses) or mental health workers recruited from community mental health clinics, participating in the RCT as part of their regular job. Among the providers, $83.9 \%$ had no prior CBT training and $75.0 \%$ had no prior experience working with anxiety (Haugland et al., 2020). The majority of providers (75\%) administered both interventions. All providers were invited to participate in the present study, except three community psychologists who had been involved during a limited part of the trial. Invitation to participate in the focus group study was forwarded by local project leaders who also conveyed an informational letter about the study. Reasons given by providers for not participating $(n=12)$ in the focus group study were maternity leave $(n=2)$, sick leave $(n=1)$, job change $(n=3)$, and not having time due to other work activities $(n=6)$. We contacted potential participants by phone to provide additional information, confirm their participation, and schedule time and date for the focus group.

Seventeen providers participated in the focus groups ( $M$ age $=44.7$ years, $\mathrm{SD}=7.0$, range $36-60 ; 88 \%$ female $)$. They were either employed by school health services (school nurse $n=11$, community psychologist $n=1$, family therapist $n=1$, special education teacher $n=1$ ) or community mental health clinics (social worker $n=2$, psychiatric nurse $n=1$ ). They had an average of 14.4 years of experience working with youth and had delivered an average of 3.7 groups each in the $\mathrm{RCT}(\mathrm{SD}=1.45)$.

\section{Implementation Context and Strategy}

In the RCT, brief (5 sessions) and standard-length (10 sessions) group-based CBT were delivered in 15 junior high schools ${ }^{1}$ from three regions of Norway in the years from 2014 to 2016. The schools were located in urban, suburban, as well as rural areas. A research team led the project organization, and each region had a local project leader, and 1-2 local coordinators. The providers carried out the recruitment and inclusion process. The providers evaluated eligible adolescents with a joint adolescent and caregiver(s) assessment interview developed for the RCT. The interview included assessment of anxiety, severity, and impairment and what goals the adolescent wanted to achieve regarding managing his/her anxiety. Providers delivered group-based CBT in pairs of two. Adolescents participating in the CBT groups had elevated anxiety symptoms (i.e., above average score on an established inventory for assessing anxiety symptoms in youth; Spence, 1998) were aged 12-16 years, 84\% girls and $96 \%$ Norwegian. See Haugland et al., (2020) for more information about the adolescents.

\section{CBT Interventions}

The interventions were manualized and included basic CBT principles for anxiety, e.g., psychoeducation, cognitive restructuring, in- and between-session exposure, and homework assignments. Two interventions were implemented, differing in number of sessions, and amount of face-to-face contact between providers and adolescents.

The brief CBT, named Vaag ${ }^{2}$ (Raknes et al., 2015) is a 5 -session group-based intervention with sessions of 45-90 min (total 5.5 h). The first four sessions occur weekly, with the fifth session following 5 weeks later (total duration

\footnotetext{
1 The term junior high school is used for the Norwegian 8th to 10th grade which is compulsory for adolescents aged 13-16 years.

2 Norwegian word meaning "dare" or "venture".
} 
of the program is 10 weeks). Between session 4 and 5, adolescents received two phone calls or text messages from the provider. Session two is a joint adolescent-parent session. Vaag was developed for the RCT.

The standard-length CBT, named Cool Kids (Rapee et al., 2006) comprise 10 weekly 90-min sessions (total $15 \mathrm{~h}$, plus two 90-min parents-only sessions). Cool Kids can be delivered to children (aged 7-12 years) and adolescents (aged 12-17 years), and the group-based, school-version for adolescents was applied in the RCT (Rapee et al., 2006). Cool Kids have previously shown efficacy and effectiveness as treatment for anxiety disorders (Mychailyszyn, 2017; Jonsson, Thastum, Arendt, \& Juul-Sorensen, 2015), and as school-based prevention (Mifsud \& Rapee, 2005; McLoone \& Rapee, 2012).

\section{Training and Supervision}

Providers received a 4-day skills-training workshop comprising basic CBT principles for adolescent anxiety, assessment procedures, and introduction to both intervention manuals. Two additional 2-day workshops were given during the project, i.e., on adolescent anxiety, recruiting adolescents, exposure training, cognitive restructuring, and group processes. The training workshops involved didactic instruction, role plays, exercises, and discussions. Network meetings for providers in the different regions were held regularly. During the administration of groups, the providers received regular supervision, by one of 10 experienced CBT therapists. The supervision was between 3 and $4.5 \mathrm{~h}$ for each Vaag group and between 6 and $10.5 \mathrm{~h}$ for each Cool Kids group. The difference in number of supervision hours between Vaag and Cool Kids was due to the difference in number of sessions in the two interventions. The supervision was delivered in accordance with a plan with instructions on duration, structure and content of the supervision, including feedback on video recordings of sessions (Haugland et al., 2020). Supervision was monitored by checklists completed by supervisors after each session (Haugland et al., 2017).

\section{Data Collection for the Focus Group Study}

Three focus group interviews were conducted between April and June 2017, one in each of the regions for the RCT. The three focus group had four, six, and seven participants, respectively. At the time of the focus group interviews, the project had been running 2.5 years, and recruitment of adolescents was finished. Furthermore, the providers participating had delivered interventions for 2 years and led $2-8$ groups each $(M=3.7, \mathrm{SD}=1.4)$. Interviews took place in the providers' work facilities during work hours. Each interview lasted about 90 min. All interviews were audio recorded and transcribed verbatim. Information that could identify providers was removed at the point of transcription, and names were replaced with pseudonyms.

\section{Focus Group Interviews}

Prior to the interviews, providers were asked to recall experiences from the implementation, including training, supervision, recruitment of adolescents, and delivery of group sessions. A clinical psychologist (first author) not participating in the implementation of the interventions nor collection of data from the RCT led the interviews. A researcher experienced in qualitative methods (last author) observed the interviews and took notes. Each focus group began with the interviewer and the observer presenting themselves. It was made clear that they were not part of the implementation of the interventions. The providers were encouraged to give concrete examples from the implementation, including training, supervision, recruitment of adolescents, assessment interviews, and delivering group sessions. The interview guide was designed with two open questions to ensure that the providers' experiences guided the conversation and shaped the data (Malterud, 2012a). The two questions were formulated to make sure the providers' spontaneous descriptions were minimally influenced by the researchers' preconceptions. Therefore, the interview guide did not specify any types of answers, nor imposed any specific assumptions on the interview (Malterud, 2012a). The open questions were (1) What have you experienced as facilitators in the project? and (2) What have you experienced as barriers in the project? Follow-up probes were used to elicit concrete examples and more detailed responses, e.g., "Can you elaborate on that?", "What exactly did they say?". A dynamic and flexible style was used by the interviewer to facilitate discussions between participants.

\section{Sample Size and Information Power}

Assessment of information power (Malterud, Siersma, \& Guassora, 2015) guided the number of focus groups. Information power refers to how researchers can achieve adequate sample size though having a clearly defined aim, a specific sample, a theoretical approach, high-quality dialog and specified analysis procedure. The larger information power the sample holds, the lower sample size is needed (Malterud, Siersma, \& Guassora, 2015). Information power and sample size were assessed throughout the data collection (Malterud, Siersma, \& Guassora, 2015). When sufficient 
information power was achieved, a responsible analysis could be performed.

\section{Analysis}

The first and last author employed Systematic Text Condensation (STC; (Malterud, 2012b) together to perform the analysis. STC is a descriptive approach, aiming to present the participants' experiences as expressed by themselves, rather than searching for potential underlying meanings in what is said (Malterud, 2012b). The method involves four steps for thematic cross-case analysis (Malterud, 2012b). In the first step, both analysts individually read the focus group transcripts to obtain an overall impression and look for preliminary themes associated with facilitators of implementation. Before the focus group interviews were conducted, the two analysts wrote down subjective preconceptions. Throughout this process, the analysts were conscious of their written subjective preconceptions. Each analyst identified 8 preliminary themes (4-8 recommended in STC; Malterud, 2012b). After the individual reading, analysts met to discuss and coordinate the preliminary themes, both confluent and divergent. Each preliminary theme was discussed to find possible agreement or disagreement between the analysts and to understand the content and meaning of the theme. Five themes were agreed upon to prioritize in the next step. In step two, analysts identified transcript excerpts reflecting aspects of providers' experiences containing information about the research question (i.e., meaning units) through several readings. The meaning units were then assigned to the previously negotiated themes they best fit with. This process involves decontextualization, where the meaning units are temporarily removed from the original context for a cross-case synthesis within the themes (Malterud, 2012b). In this way, the preliminary themes were developed, elaborated, and formed into four code groups informed by the meaning units in an iterative process (Malterud, 2012b). By continuously checking with preconceptions, code groups were made sure to not only mirror previous knowledge.

According to recommendations by Malterud (2012b), analysts now reviewed whether the data contained abundant and diverse accounts associated with the research question or if more data collection was needed. In light of the rich content in the identified code groups, we decided the data were sufficient to continue analysis. In step three, meaning units within each code group were systematically abstracted. Within each code group, subgroups exemplifying vital aspects of the code group were established by identifying specific illustrative quotations for each. Each meaning unit in each subgroup was reviewed in order to condense the content into a first-person "one-voice" quotation for each subgroup. Through this process, the two to three aspects representing the thematic content of each code group are abstracted, adjusted, and refined (Malterud, $2012 b$ ). In the fourth step, each code group was re-written into a third-person conceptual description, representing experiences shared by several providers. This was done to re-contextualize the experiences. By returning to the full transcripts, analysts validated that the conceptual descriptions for each code group reflected the context they were collected from Malterud (2001). The conceptual descriptions and their headings, a further concentration of the code group, are the results presented in the result section. Finally, analysts systematically searched through their subjective preconceptions and the full transcripts for data that could challenge the findings. The second and third author of the current study were consulted for feedback and input in stage three and four of the STC. This made sure the data were understood from multiple perspectives and led to further refinement of the code groups. A theoretically integration of the findings is presented in the discussion, allowing for a more complete understanding of the results (Nilsen, 2015).

\section{Results}

Findings are presented below in four main themes derived from the analysis; Building competence and confidence through training, supervision, and collegial support; The value of the initial assessment interview; Experiencing that "it actually works", but different interventions may fit different adolescents; and Crucial cooperation with the schools. The themes detail the providers' experiences with implementing targeted prevention in the form of group-based CBT in a school setting in Norway.

\section{Building Competence and Confidence Through Training, Supervision, and Collegial Support}

The majority of the providers expressed the implementation process as an experience of gaining increased competence while being in an environment of collegial cooperation. They highlighted the skill-based training at the start of and during the project as important for feeling competent in intervention delivery. Exposure is an essential intervention in CBT for anxiety and many of the providers expressed that it was valuable to have performed exposure exercises themselves during the training, to be able to later gently push the adolescents to face their fears during the group interventions. Several of the providers mentioned that preparing and performing the first group meetings were very time consuming, and in the beginning, their main focus was on adhering to the manual. As they became more experienced, they 
needed less time for preparation, became more flexible and more able to adapt the program to individual needs, and also to engage the adolescents in the process. With increasing confidence, the providers managed to do exposure exercises with the adolescents in earlier sessions. When delivering the first group(s), some providers experienced themselves as too gentle and being afraid of making the adolescents uncomfortable. However, with experience and supervision, they learned to gently push the adolescents to challenge themselves. All providers appreciated close supervision on how to administer the manual. They expressed that the video recordings from group sessions also facilitated the supervision. They appreciated that the supervisors were constructive and goal-oriented. They enjoyed working in pairs (two providers per group) and experienced this as a positive change from their everyday, more solitary work. The collaboration with colleagues increased their tolerance for and competence in both giving and receiving constructive feedback. Meeting and discussing with other providers in the network meetings were also mentioned by several as a crucial part of the learning process. A provider said she went from feeling small and alone and thinking that everybody else knew much more than her, to acknowledging that they all struggled with the same challenges.

"...hearing that others [providers at other schools] have the same challenges as us, that we have been sitting here feeling incompetent. But then realizing that we all strive with the same challenges." Mary

\section{The Value of the Initial Assessment Interview}

According to several providers the assessment interview in the inclusion process served multiple purposes. During the interview, the parents gained valuable insight. Many parents did not know or had not realized how much their adolescent struggled with anxiety, before hearing their adolescent describe their problems in detail during the assessment interview. A few providers emphasized that the adolescents seemed more motivated to participate in the group interventions after having completed the assessment interview. They hypothesized that this was due to the time and effort the youth invested in doing both the assessment interview and the digital questionnaires. Also, the providers benefited from the information gathered about the adolescents' problems in the assessment interviews. One provider explained how the information from the assessment interview helped them tailor the group sessions to the adolescents' need:

“...in a recent group, actually three adolescents did not sleep in their own bed. But none of them wanted to expose themselves. So, we made a case for them to discuss about a boy struggling to sleep in his own room [...]. And it wasn't until next session, I think, that one of them revealed that "last time you talked about me". And then, you know, we could start talking about it, and the others saw it wasn't that dangerous to talk about." Sue

\section{Experiencing That "it actually works", But Different Interventions May Fit Different Adolescents}

Watching adolescents being empowered and becoming less anxious through participating in CBT groups, and parents being thankful for the change they observed in their adolescent, gave the providers experiences of success and boosted their motivation for continuing the groups and practicing their new skills. Several providers said they initially thought that much more intensive interventions were needed for adolescents to learn to combat anxiety symptoms. They were baffled by the changes they saw in the adolescents completing the CBT groups. A provider expressed that observing changes in the adolescents motivated her to continue recruiting and administering the interventions:

"I think that the biggest motivation was that after the first group I saw that it worked. This was new to me, so when I heard from the parents that "wow, our daughter has really changed", or I saw that someone suddenly dealt with the problem differently. That was motivating. Much more than all the research behind it, seeing in practice/real life that it actually works!" Ruth

While delivering two different interventions, the providers reflected on whether they might fit better for different adolescents. The providers discussed the strengths they experienced in each of the two programs delivered. One school nurse had a group where they delivered the 10 -session program. In this group, three of five adolescents dropped-out. She hypothesized that the theory-loaded first sessions of the program were too difficult for the members of this group, who had either dyslexia or other learning disabilities. Other providers highlighted how the stricter schedule of the 5-session intervention could facilitate a good progress. However, the strict schedule could also be a barrier when adolescents expressed issues the provider wanted to explore further, rather than having to move forward according to the manual. Several providers considered the 10-session intervention to be a better fit for those with good cognitive resources and moderate anxiety, while they experienced the 5 -session intervention as a better fit for those with mild anxiety and/or limited cognitive resources. One provider said: 
"[...] we have some experiences with two adolescents where we thought, wow, we think these adolescents strive more than what we can help them with within the 5-session intervention." Liz

\section{Crucial Cooperation with the Schools}

The providers stressed the importance of the interventions being part of everyday life in the schools. Conducting the groups at school, during school hours, made it easier to knock on the classroom door and fetch adolescents who didn't come to appointments or group meetings. Several providers mentioned the teachers as important collaborators for recruitment and facilitation of the interventions. Some providers regularly had lunch with the teachers to build relationships with them. The collaboration between providers and teachers was further expressed by the providers helping teachers to identify adolescents that were in the target group for the anxiety interventions, e.g., school nurses made checklist for the teachers on what to look for to recognize anxious adolescents in the classroom. As teachers became more aware of signs of anxiety symptoms, they more often nominated eligible adolescents for the interventions. Several providers noted that as soon as teachers themselves saw that their students changed due to the intervention, recruitment of adolescent became easier. One participant said:

"There had to be success stories within the school, so that a teacher could stand in front of all the others and tell that he had had a student in the CBT groups, and that she had become a different (new) person in class. That's when it started to roll. They [the teachers] had to sell it among themselves, in a way, it wasn't enough that we told them. Because we felt that we had said it so many times, without much success." Sophie

Whereas the majority of the providers experienced the teachers as helpful and facilitative in scheduling group meetings and allowing pupils to attend, a few had negative experiences with teachers who lowered the adolescents' grades due to the absence from class because of group meetings. Teachers helped some providers schedule the intervention sessions, and some teachers rescheduled tests so that their students could participate in planned intervention sessions. One principal had introduced the project to the teachers by saying "we will do this together", and that made it a lot easier to onboard the teachers, to recruit and support adolescents who attended group meetings. At one school, the principal tried to overrun the project by suggesting that teachers should deliver the interventions, instead of the school nurses, which was not complied to.

\section{Discussion}

This study was designed to explore factors facilitating the implementation of group-based interventions within school settings, by exploring providers' experiences of administering targeted prevention for adolescents with anxiety symptoms. The results highlighted several facilitators. The following four themes were identified, based on a qualitative analysis (Malterud, 2012b) of providers' experiences; (1) the providers gained crucial competence and increasing confidence from skills-based training, practice, supervision, as well as by support from colleagues. (2) Initial assessment interviews with adolescents and caregiver(s) facilitated tailoring the group-based intervention to the individual adolescent, increasing adolescent and parent motivation, (3) observing changes in the adolescents in how they managed their anxiety, motivated the providers to continue to recruit adolescents and implement the interventions. With increasing experience, the providers were able to reflect on which intervention fit different adolescents, based on the participants' cognitive abilities and severity of anxiety symptoms. (4) Cooperation with teachers were deemed important for successful recruitment of adolescents and the delivery of the interventions.

The Active Implementation framework (AIF) represents an overarching framework that may contextualize these findings (Bertram, Blase, \& Fixsen, 2015; Fixsen, Blase, Naoom, \& Wallace, 2009). Our findings are related to both competency drivers, e.g., providers reporting feeling confident and competent after skills-based training and supervision, and to organization drivers, e.g., providers reporting that working in pairs was appreciated and meeting a broader group of providers from other schools created a feeling of cohesion and confidence. Interestingly, leadership-oriented drivers were only commented on in two concrete experiences where the principal leadership was mentioned. Thus, our findings have limited overlap regarding the leadership drivers in AIF.

The providers conveyed experiences of steadily increasing confidence and mastery in delivering the interventions. They linked this with the training and supervision they received, in keeping with the competency drivers in AIF. Didactic training, e.g., introduction to manuals and skills-based training, with role plays are important, however, not sufficient for positive outcomes to occur (Herschell, Kolko, Baumann, \& Davis, 2010; Beidas \& Kendall, 2010). Ongoing supervision attuned to each provider's needs is also imperative (Schoenwald, Sheidow, \& Letourneau, 2004; Bertram, Blase, Shern, \& Fixsen, 2011). In the current study, supervisors were external (i.e., not employed by the school health services) CBT therapists. Associations between highly trained supervisors, therapist adherence to the program, and better 
adolescent outcomes have been found in a previous study (Schoenwald, Sheidow, \& Letourneau 2004). Using external supervisors may be more costly, but is necessary when the needed competence is not available in the implementation setting. Further, evidence show that adherence to program manuals may decline rapidly in the absence of ongoing supervision of school providers (Masia Warner et al., 2013), emphasizing the importance of regular and ongoing supervision.

Ongoing collegial support from other providers of the interventions was also highlighted by the providers. Similar findings have been found by others who underline that being more than one provider of an intervention in the same organization is a facilitator to implementation (Klest, 2014; Patras \& Klest, 2016; Nielsen, Weie Oddli, Slinning, \& Drozd, 2020). Further, taking part in a network with other providers of an intervention have also been reported as a factor contributing to successful implementation of schoolbased CBT for trauma (Langley, Nadeem, Kataoka, Stein, \& Jaycox, 2010). Meeting other providers may be experienced as supportive by having someone to turn to and ask for help when they experience challenges. This suggests positive outcome of organizing implementation efforts in such a way that providers work in pairs and have regular meetings with several peer providers.

Lack of parental involvement has been reported as a barrier to implementation of school-based intervention for trauma (Langley, Nadeem, Kataoka, Stein, \& Jaycox, 2010). The providers in the current study highlighted that conducting the assessment interview, involving parent(s) and adolescent, was a facilitator because it increased the parents' understanding of their adolescent's anxiety. Parents may often not be aware of or understand their adolescent's internalizing symptoms (Youngstrom, Loeber, \& StouthamerLoeber, 2000). Thus, the parents getting insight into the anxiety symptoms and the consequences of their adolescent's problems may be important for parents to be involved in the intervention. Further, the providers assessing adolescents may be an example of an organization driver component integrated with a competency driver component (Fixsen, Blase, Naoom, \& Wallace, 2009), as providing the assessment interview involves both an adjustment in the organization (the school) and an increase in the competence of the providers. A recent study found that school health personnel in the USA rarely know any assessment instruments or how to use them (Muggeo \& Ginsburg, 2019). Our findings show that, according to the providers, systematic assessment help them to individually adapt group interventions to each participants' needs, functioning and goals.

Some providers expressed that experiencing positive outcomes in participating adolescents was more motivating than the research evidence presented to them during training. Furthermore, Powell, Hausmann-Stabile, \& McMillen,
(2013) identified lived experiences of client change as an important implementation incentive for mental health clinicians in the USA. Our finding underlines the importance of ensuring that training and supervision are maintained, at least until providers have conducted a few intervention groups and gained experiences of positive adolescent outcomes. If providers do not deliver intervention successfully to adolescents and therefore do not achieve expected positive outcomes, they will likely not experience the facilitation of lived clinical experience of effectiveness. Thus, implementation support should be continued at least throughout the first finished groups, so providers may experience seeing positive outcomes in adolescents, and be motivated to continue to implement the intervention. This is also corroborated by Han and Weiss (2005) who suggested that training and regular supervision should be continued as an ongoing implementation factor in school interventions.

By delivering two interventions, differing primarily in number and length of sessions, the providers attained experience about which intervention might suit different adolescents. Interestingly, the providers seemed more interested in this, than what intervention would best 'fit' their organization. This is in line with results from a study on school health personnel, who discussed the fit of an intervention, reporting factors related to their clients or themselves, and discussing only few perspectives on the fit to their organization (Lyon et al., 2014). An interpretation of our finding could be that both the brief and the standard intervention were acceptable for the schools.

Experiences shared by the providers in the current study suggest that they did not manage to fully deliver the interventions with flexibility, and according to the individual needs of the individual adolescent. Both intervention manuals instruct providers to adjust sessions to the adolescents' abilities and needs (Rapee et al., 2006; Raknes et al., 2015). Therefore, adolescent characteristics mentioned, e.g., dyslexia, severity of anxiety symptoms, cognitive abilities, could have been subject to adjustments within the programs. Flexibility within fidelity refers to the process of adapting an intervention based on available research evidence, e.g., as stated in the manual, clinical expertise, and client characteristics (Kendall \& Beidas, 2007; Kendall \& Frank, 2018). Both intervention manuals allowed providers to shorten sessions, add more sessions, or increase session length if needed. Further, the manuals allowed for extended time used on specific themes that seemed difficult to understand for the adolescents. If providers saw that the content would be too challenging for some adolescents, they could have simplified it. Also, they could have shortened the 10-session intervention for adolescents with only mild anxiety symptoms and who were not in need of a standard-length interventions. Still, based on the providers' experiences, assessment of cognitive abilities and severity of anxiety may be important 
dimensions to consider when implementing school-based interventions.

Our findings suggest that although teachers were not involved in the delivery of the interventions, their contributions were important in recruiting adolescents and facilitating group participation. The providers valued close contact with teachers to foster support from them. This may illustrate the importance of organization drivers, as it relates to whether the climate in the organization is supporting implementation (Langley, Nadeem, Kataoka, Stein, \& Jaycox, 2010). Interestingly, prior research has found that teachers express a need for close communication with school providers (Baweja et al., 2016). Further, recruitment boosted when teachers saw positive outcomes and began advocating for the interventions to their fellow teachers. This is in line with findings that teachers are important for implementation by encouraging other teachers to accept new interventions (Beets et al., 2008). If an opinion-leader among teachers endorse a new intervention, it may impact his/her colleagues to also endorse the intervention (Atkins et al., 2008). Further, a previous study found that lack of support from teachers and school administrators were among the top implementation barriers reported by providers (Langley, Nadeem, Kataoka, Stein, \& Jaycox, 2010). Thus, encouraging providers to engage closely with teachers may be crucial for successful implementation of school-based interventions.

Invested principals have previously been identified as important for successful implementation of school-based interventions (Langley, Nadeem, Kataoka, Stein, \& Jaycox, 2010). However, the current study had few leadership-oriented findings. AIF stipulates an integrative and compensatory manner in which the drivers together contribute to successful implementation (Blase, van Dyke, \& Fixsen, 2013). Thus, according to AIF, we may assume that the other facilitators present, e.g., supervision and collegial support, have attuned the lack of leadership-oriented facilitators present. However, we cannot rule out the possibility that the providers may have perceived support from their leaders (e.g., principal, head nurse) as an implicit or obvious issue, and therefore did not articulate this as a facilitating factor. Alternatively, the leadership in the participating schools may have been "good enough", so that it was neither facilitating nor hampering the implementation. The schools volunteered to take part in the study, indicating that the principals were positive to and supportive of the interventions. Another possibility is that principal leadership may not have been specifically important for the current implementation, due to the project organization. The implementation project had a multifaceted leadership, as the research project leader, local project leader (e.g., head school nurse or community psychologist) and local coordinators (e.g., an experienced school nurse with high credibility) functioned as leaders for the providers. They kept close contact with the providers (Haugland et al.,
2020), and may to some degree have reduced the importance of the school leaders beyond accepting the intervention to take place in their school. This is in line with findings from implementation of evidence-based trauma interventions in schools, where leaders of school health services were found crucial for implementation success, while principals were not mentioned (Nadeem, Saldana, Chapman, \& Schaper, 2018). However, that study relied on interviews with leaders, which may have a different perspective than providers.

\section{Methodological Discussion}

The study has several strengths. The inductive qualitative approach gave insights into experiences of providers of targeted prevention for anxiety in the school setting. Our findings extend the literature by highlighting leverage points that may inform implementation of future school-based interventions. The research was conducted by closely following the methodological guidelines of Malterud (2012b). The study also meets the criteria of the COREQ guidelines for rigorous reporting of qualitative research (Tong, Sainsbury, \& Craig, 2007).

The number of focus groups was guided by an evaluation of information power from planning through data collection (Malterud, Siersma, \& Guassora, 2015). After three focus groups, we assessed that sufficient information power was achieved due to five items. Firstly, the study had a specific aim (i.e., to explore providers' experiences of factors facilitating successful implementation of targeted prevention for adolescent anxiety symptoms in schools). Secondly, we had a sample with high specificity related to the aim. That is, the providers interviewed had all been extensively involved in the implementation of school-based anxiety interventions while still having some variation in experiences (Malterud, Siersma, \& Guassora, 2015). Providers interviewed were diverse in age and educational background and had delivered 2-8 groups each. Additionally, the sample was similar to the total pool of providers in the RCT in terms of age, gender, and education. We considered that the providers' perspectives on implementing interventions in the specific setting were based on a broad range of experiences and provided a range of perspectives and nuances to the data. Thirdly, the focus groups had strong dialogs where the providers gave an adequate supply of the requested experiences (Morgan, 1997). The participants knew each other from before and shared experiences in an atmosphere of mutual trust. This was shown by follow-up questions and associations from other participants, and few interruptions or periods of silence. Forth, we integrated the results with established implementation theory (AIF; (Bertram, Blase, \& Fixsen, 2015; Fixsen, Blase, Naoom, \& Wallace, 2009) which contributed to an understanding of relations between the findings. Fifth, data were analyzed with a cross-case 
analysis strategy. Although a cross-case analysis requires a larger sample compared to, for example, a narrative analysis (Malterud, Siersma, \& Guassora, 2015), the clear and specified steps of the STC strategy contributes to information power.

A limitation in this study is that we did not consult other key stakeholders in the implementation process, i.e., adolescent participants/non-participants, school leaders/ principals, teachers and/or parents, who could have provided additional insights. We limited the scope to providers because they had the main responsibility for the implementation of the interventions. Of those invited, 12 providers declined to participate. We do not know how their input would have impacted our results. However, the reasons they provided for not participating (e.g., maternity leave, job change, sick leave) indicate factors not related to the implementation process or the interventions (e.g., discontent with the project/interventions).

The facilitators addressed in this study should not be considered to be exhaustive. However, the described factors are in accordance with other research findings, suggesting that these are factors that are found to be important across settings and samples. Thus, the factors described by providers as important for implementing targeted prevention for adolescents with anxiety are assumed to be of relevance to implementation of similar school-based interventions. Although the organization of the implementation was comparable in the three regions, including providers from each region provided experiences from different local contexts. Further, there are small differences across regions and areas concerning standard of living and income in Norway (OECD 2020a, b). Thus, geographical differences should not impact our findings.

\section{Conclusion}

This study offers provider perspectives on implementation of targeted prevention for anxiety symptoms in adolescents, delivered in the school setting by school providers (i.e., school nurses, social workers). Our results show that providers trained to deliver anxiety CBT group interventions in schools experience mastery and feeling of competence when receiving support, training, and supervision. Our findings align with the organization and competency drivers in AIF and may guide prioritization in future implementation efforts of school-based prevention.

Acknowledgements Open Access funding provided by University of Bergen. Thanks to all participants and colleagues who made this study possible.
Authors' Contributions BSMH, GJW, EH conceptualized the study, BSMH, GJW, EH and SM planned the study. EH and SM conducted the focus group interview and analysis. All authors contributed to the manuscript.

Funding This study was funded by The Western Norway Health Authority (Grant No. 912026), the Norwegian Research Council (Grant No. 229020), and Regional Center for Child and Youth Mental Health and Child Welfare, NORCE Norwegian Research Center.

\section{Compliance with Ethical Standards}

Conflict of interest The authors declare that they have no competing interests.

Ethics Approval and Consent to Participate Principles of the Helsinki declaration were followed, and written informed consent was obtained from all participants prior to participation. Approval for the study was obtained from the Data Protection Official for Research, which is the data protection authority in Norway (ID 53716).

Consent for Publication Not applicable.

Availability of Data and Material The transcripts analyzed during the current study are available from the corresponding author on reasonable request.

Code Availability Available from the corresponding author on reasonable request.

Open Access This article is licensed under a Creative Commons Attribution 4.0 International License, which permits use, sharing, adaptation, distribution and reproduction in any medium or format, as long as you give appropriate credit to the original author(s) and the source, provide a link to the Creative Commons licence, and indicate if changes were made. The images or other third party material in this article are included in the article's Creative Commons licence, unless indicated otherwise in a credit line to the material. If material is not included in the article's Creative Commons licence and your intended use is not permitted by statutory regulation or exceeds the permitted use, you will need to obtain permission directly from the copyright holder. To view a copy of this licence, visit http://creativecommons.org/licenses/by/4.0/.

\section{References}

Angold, A., Costello, E. J., Farmer, E. M. Z., Burns, B. J., \& Erkanli, A. (1999). Impaired but undiagnosed. Journal of the American Academy of Child and Adolescent Psychiatry, 38(2), 129-137. https://doi.org/10.1097/00004583-199902000-00011.

Atkins, M. S., Frazier, S. L., Leathers, S. J., Graczyk, P. A., Talbott, E., Jakobsons, L., et al. (2008). Teacher key opinion leaders and mental health consultation in low-income urban schools. Journal of Consulting and Clinical Psychology. https://doi.org/10.1037/ a0013036.

Balazs, J., Miklosi, M., Kereszteny, A., Hoven, C. W., Carli, V., Wasserman, C., et al. (2013). Adolescent subthreshold-depression and anxiety: psychopathology, functional impairment and increased suicide risk. Journal of Child Psychology and Psychiatry, 54(6), 670-677. https://doi.org/10.1111/jcpp.12016.

Baweja, S., Santiago, C. D., Vona, P., Pears, G., Langley, A., \& Kataoka, S. (2016). Improving implementation of a school-based program for traumatized students: Identifying factors that promote 
teacher support and collaboration. School Mental Health, 8(1), 120-131. https://doi.org/10.1007/s12310-015-9170-z.

Beets, M., Flay, B., Vuchinich, S., Acock, A., Li, K. K., \& Allred, C. (2008). School climate and teachers' beliefs and attitudes associated with implementation of the positive action program: A diffusion of innovations model. Prevention Science, 9(4), 264-275. https://doi.org/10.1007/s11121-008-0100-2.

Beidas, R. S., \& Kendall, P. C. (2010). Training therapists in evidencebased practice: A critical review of studies from a systems-contextual perspective. Clinical Psychology: Science and Practice, 17(1), 1-30. https://doi.org/10.1111/j.1468-2850.2009.01187.x.

Beidas, R. S., Mychailyszyn, M. P., Edmunds, J. M., Khanna, M. S., Downey, M. M., \& Kendall, P. C. (2012). Training school mental health providers to deliver cognitive-behavioral therapy. School Mental Health, 4(4), 197-206. https://doi.org/10.1007/s1231 0-012-9074-0.

Bertram, R. M., Blase, K. A., \& Fixsen, D. L. (2015). Improving programs and outcomes: Implementation frameworks and organization change. Research on Social Work Practice, 25(4), 477-487. https://doi.org/10.1177/1049731514537687.

Bertram, R. M., Blase, K., Shern, P., \& Fixsen, D. (2011). Policy research brief: Opportunities and challenges for prevention and promotion initiatives. Alexandria, VA: National Association of State Mental Health Program Directord (NASMHPD).

Blase, K., van Dyke, M., \& Fixsen, D. (2013). Education implementation drivers assessing best practices.

Blase, K., van Dyke, M., Fixsen, D., \& Bailey, F. W. (2012). Key concepts, themes, and evidence for practitioners in educational psychology. In B. Kelly \& D. F. Perkins (Eds.), Handbook of Implementation Science for Psychology in Education (pp. 13-34). Cambridge: Cambridge University Press.

Chavira, D. A., Stein, M. B., Bailey, K., \& Stein, M. T. (2004). Child anxiety in primary care: Prevalent but untreated. Depression and Anxiety, 20(4), 155-164. https://doi.org/10.1002/da.20039.

Essau, C. A. (2005). Frequency and patterns of mental health services utilization among adolescents with anxiety and depressive disorders. Depression and Anxiety, 22(3), 130-137. https://doi. org/10.1002/da.20115.

Evans, S. W., Koch, J. R., Brady, C., Meszaros, P., \& Sadler, J. (2013). Community and school mental health professionals' knowledge and use of evidence based substance use prevention programs. Administration and Policy in Mental Health and Mental Health Services Research, 40(4), 319-330. https://doi.org/10.1007/s1048 8-012-0422-z.

Fabiano, G. A., \& Evans, S. W. (2018). Introduction to the special issue of school mental health on best practices in effective multi-tiered intervention frameworks. School Mental Health, 11(1), 1-3. https ://doi.org/10.1007/s12310-018-9283-2.

Fazel, M., Hoagwood, K., Stephan, S., \& Ford, T. (2014). Mental health interventions in schools in high-income countries. Lancet Psychiatry, 1(5), 377-387. https://doi.org/10.1016/S2215 $-0366(14) 70312-8$.

Fixsen, D. L., Blase, K. A., Metz, A., \& Van Dyke, M. (2015a). Implementation science. In J. D. Wrigth (Ed.), International Encyclopedia of the Social and Behavioral Sciences (2nd ed., Vol. 11, pp. 695-702). Oxford: Elsevier.

Fixsen, D. L., Blase, K., Naoom, S., \& Duda, M. (2015b). Implementation Drivers: Assessing Best Practices. Chapel Hill: National Implementation Research Network, University of North Carolina at Chapel Hill.

Fixsen, D. L., Blase, K. A., Naoom, S. F., \& Wallace, F. (2009). Core implementation components. Research on Social Work Practice, 19(5), 531-540. https://doi.org/10.1177/1049731509335549.

Fixsen, D. L., Naoom, S., Blasé, K., Friedman, R., \& Wallace, F. (2005). Implementation research: A synthesis of the Literature.
Forman, S. G., \& Barakat, N. M. (2011). Cognitive-behavioral therapy in the schools: Bringing research to practice through effective implementation. Psychology in the Schools, 48(3), 283-296. https ://doi.org/10.1002/pits.20547.

Forman, S. G., Olin, S. S., Hoagwood, K. E., Crowe, M., \& Saka, N. (2008). Evidence-based interventions in schools: Developers' views of implementation barriers and facilitators. School Mental Health, 1(1), 26-36. https://doi.org/10.1007/s12310-008-9002-5.

Forman, S. G., Ward, C. S., \& Fixsen, D. L. (2017). Comprehensive behavioral health and school psychology: An implementation agenda. Journal of Applied School Psychology, 33(3), 233-244. https://doi.org/10.1080/15377903.2017.1317153.

Foster, S. L., Rollefson, M., Hoagwood, K., Crowe, M., \& Saka, N. (2009). School Mental Health Services in the United States, 2002 2003. Center for Mental Health Services, Substance Abuse and Mental Health Services Administration. DHHS Pub. No. (SMA) 05-4068. https://eric.ed.gov/?id=ED499056.

Han, S. S., \& Weiss, B. (2005). Sustainability of teacher implementation of school-based mental health programs. Journal of Abnormal Child Psychology, 33(6), 665-679. https://doi.org/10.1007/ s10802-005-7646-2.

Haugland, B. S. M., Haaland, A. T., Baste, V., Bjaastad, J. F., Hoffart, A., Rapee, R. M., et al. (2020). Effectiveness of brief and standard school-based cognitive-behavioral interventions for adolescents with anxiety: A randomized non-inferiority study. Journal of the American Academy of Child and Adolescent Psychiatry. https:// doi.org/10.1016/j.jaac.2019.12.003.

Haugland, B. S. M., Raknes, S., Haaland, A. T., Wergeland, G. J., Bjaastad, J. F., Baste, V., et al. (2017). School-based cognitive behavioral interventions for anxious youth: Study protocol for a randomized controlled trial. Trials, 18(1), 100. https://doi. org/10.1186/s13063-017-1831-9.

Herschell, A. D., Kolko, D. J., Baumann, B. L., \& Davis, A. C. (2010). The role of therapist training in the implementation of psychosocial treatments: A review and critique with recommendations. Clinical Psychology Review, 30(4), 448-466. https ://doi.org/10.1016/j.cpr.2010.02.005.

Ivanoff, S. D., \& Hultberg, J. (2006). Understanding the multiple realities of everyday life: Basic assumptions in focus-group methodology. Scandinavian Journal of Occupational Therapy, 13(2), 125-132. https://doi.org/10.1080/11038120600691082.

Jones, A. M., West, K. B., \& Suveg, C. (2019). Anxiety in the school setting: A framework for evidence-based practice. School Mental Health, 11(1), 4-14. https://doi.org/10.1007/s1231 0-017-9235-2.

Jonsson, H., Thastum, M., Arendt, K., \& Juul-Sorensen, M. (2015). Group cognitive behavioural treatment of youth anxiety in community based clinical practice: Clinical significance and benchmarking against efficacy. Journal of Anxiety Disorders, 35, 9-18. https://doi.org/10.1016/j.janxdis.2015.06.009.

Kendall, P. C., \& Beidas, R. S. (2007). Smoothing the trail for dissemination of evidence-based practices for youth: Flexibility within fidelity. Professional Psychology-Research and Practice, 38(1), 13-20. https://doi.org/10.1037/0735-7028.38.1.13.

Kendall, P. C., \& Frank, H. E. (2018). Implementing evidence-based treatment protocols: Flexibility within fidelity. Clinical Psychology: Science and Practice. https://doi.org/10.1111/cpsp.12271.

Kitzinger, J., Pope, C., \& Mays, N. (2006). Qualitative Research in Health Care. Focus Groups (3rd ed.). Oxford: Blackwell Publishing Ltd.

Klest, S. K. (2014). Clustering practitioners within service organizations may improve implementation outcomes for evidence-based programs. Zeitschrift Fur Psychologie-Journal of Psychology, 222(1), 30-36. https://doi.org/10.1027/2151-2604/a000163.

Krueger, R. A., \& Casey, M. A. (2000). Focus Groups: A Practical Guide for Applied Research (3rd ed.). Thousand Oaks: Sage. 
Langley, A. K., Nadeem, E., Kataoka, S. H., Stein, B. D., \& Jaycox, L. H. (2010). Evidence-based mental health programs in schools: Barriers and facilitators of successful implementation. School Ment Health, 2(3), 105-113. https://doi.org/10.1007/s1231 0-010-9038-1.

Lyon, A. R., \& Bruns, E. J. (2019). From evidence to impact: Joining our best school mental health practices with our best implementation strategies. School Mental Health: A Multidisciplinary Research and Practice Journal (Pagination). https://doi. org/10.1007/s12310-018-09306-w.

Lyon, A. R., \& Koerner, K. (2016). User-centered design for psychosocial intervention development and implementation. Clinical Psychology: Science and Practice, 23(2), 180-200. https://doi. org/10.1111/cpsp.12154.

Lyon, A. R., Ludwig, K., Romano, E., Koltracht, J., Stoep, A. V., \& McCauley, E. (2014). Using modular psychotherapy in school mental health: Provider perspectives on intervention-setting fit. Journal of Clinical Child and Adolescent Psychology, 43(6), 890-901. https://doi.org/10.1080/15374416.2013.843460.

Malterud, K. (2001). Qualitative research: Standards, challenges, and guidelines. The Lancet, 358(9280), 483-488. https://doi. org/10.1016/s0140-6736(01)05627-6.

Malterud, K. (2012a). Fokusgrupper som forskningsmetode for medisin og helsefag. [Focus Groups as a Research Method in Medical and Health Research] (1st ed.). Norway: Universitetsforlaget.

Malterud, K. (2012b). Systematic text condensation: A strategy for qualitative analysis. Scandinavian Journal of Public Health, 40(8), 795-805. https://doi.org/10.1177/1403494812465030.

Malterud, K., Siersma, V. D., \& Guassora, A. D. (2015). Sample size in qualitative interview studies: Guided by information power. Qualitative Health Research. https://doi.org/10.1177/10497 32315617444.

Masia Warner, C., Brice, C., Esseling, P. G., Stewart, C. E., Mufson, L., \& Herzig, K. (2013). Consultants' perceptions of school counselors' ability to implement an empirically-based intervention for adolescent social anxiety disorder. Administration and Policy In Mental Health, 40(6), 541-554. https://doi. org/10.1007/s10488-013-0498-0.

Masia Warner, C., Colognori, D., Brice, C., Herzig, K., Mufson, L., Lynch, C., et al. (2016). Can school counselors deliver cognitive-behavioral treatment for social anxiety effectively? A randomized controlled trial. Journal of Child Psychology and Psychiatry, 57(11), 1229-1238. https://doi.org/10.1111/ jcpp. 12550.

Mazzone, L., Ducci, F., Scoto, M. C., Passaniti, E., D’Arrigo, V. G., \& Vitiello, B. (2007). The role of anxiety symptoms in school performance in a community sample of children and adolescents. BMC Public Health, 7, 347. https://doi. org/10.1186/1471-2458-7-347.

McLoone, J. K., \& Rapee, R. M. (2012). Comparison of an anxiety management program for children implemented at home and school: Lessons learned. School Mental Health, 4(4), 231-242. https://doi.org/10.1007/s12310-012-9088-7.

Merikangas, K. R., He, J. P., Burstein, M., Swendsen, J., Avenevoli, S., Case, B., et al. (2011). Service utilization for lifetime mental disorders in U.S. Adolescents: Results of the national comorbidity survey-adolescent supplement (NCS-A). Journal of the American Academy of Child and Adolescent Psychiatry, 50(1), 32-45. https ://doi.org/10.1016/j.jaac.2010.10.006.

Mifsud, C., \& Rapee, R. M. (2005). Early intervention for childhood anxiety in a school setting: Outcomes for an economically disadvantaged population. Journal of the American Academy of Child and Adolescent Psychiatry, 44(10), 996-1004. https://doi. org/10.1097/01.chi.0000173294.13441.87.

Morgan, D. L. (1997). Focus Groups as Qualitative Research (2nd ed.). Thousand Oaks: Sage Publications.
Muggeo, M. A., \& Ginsburg, G. S. (2019). School nurse perceptions of student anxiety. Journal of School Nursing, 35(3), 163-168. https ://doi.org/10.1177/1059840517752457.

Muggeo, M. A., Stewart, C. E., Drake, K. L., \& Ginsburg, G. S. (2017). A school nurse-delivered intervention for anxious children: An open trial. School Mental Health, 9(2), 157-171. https://doi. org/10.1007/s12310-017-9211-x.

Murphy, J. M., Abel, M. R., Hoover, S., Jellinek, M., \& Fazel, M. (2017). Scope, Scale, and dose of the World's largest school-based mental health programs. Harvard Review of Psychiatry. https:// doi.org/10.1097/HRP.0000000000000149.

Mychailyszyn, M. P. (2017). "Cool" youth: A systematic review and comprehensive meta-analytic synthesis of data from the cool kids family of intervention programs. Canadian Psychology-Psychologie Canadienne, 58(2), 105-115. https://doi.org/10.1037/cap00 00101.

Nadeem, E., Saldana, L., Chapman, J., \& Schaper, H. (2018). A mixed methods study of the stages of implementation for an evidencebased trauma intervention in schools. Behavior Therapy, 49(4), 509-524. https://doi.org/10.1016/j.beth.2017.12.004.

Nielsen, B., Weie Oddli, H., Slinning, K., \& Drozd, F. (2020). Implementation of attachment-based interventions in mental health and social welfare services: Therapist's experiences from the Circle of Security-Virginia Family intervention. Children and Youth Services Review. https://doi.org/10.1016/j.childyouth.2019.104550.

Nilsen, P. (2015). Making sense of implementation theories, models and frameworks. Implementation Science, 10(1), 1-13. https://doi. org/10.1186/s13012-015-0242-0.

Norwegian Directorate of Health (2019). National proffesional guidelines for health services and school health services: School health services for 5-20 year-olds Oslo: Norway.

Novins, D. K., Green, A. E., Legha, R. K., \& Aarons, G. A. (2013). Dissemination and implementation of evidence-based practices for child and adolescent mental health: A systematic review. Journal of the American Academy of Child and Adolescent Psychiatry, 52(10), 1009-1025. https://doi.org/10.1016/j.jaac.2013.07.012.

OECD. (2020a). How's Life in Norway? Paris: OECD.

OECD (2020b). Regional Well-Being in OECD Countries: Norway. OESC.

Ogden, T., Bjornebekk, G., Kjobli, J., Patras, J., Christiansen, T., Taraldsen, K., et al. (2012). Measurement of implementation components ten years after a nationwide introduction of empirically supported programs - a pilot study. Implementation Science. https ://doi.org/10.1186/1748-5908-7-49.

Parhiala, P., Ranta, K., Gergov, V., Kontunen, J., Law, R., La Greca, A. M., et al. (2019). Interpersonal counseling in the treatment of adolescent depression: A randomized controlled effectiveness and feasibility study in school health and welfare services. School Mental Health, 12(2), 265-283. https://doi.org/10.1007/s1231 0-019-09346-w.

Patras, J., \& Klest, S. (2016). Group size and therapists' workplace ratings: Three is the magic number. Journal of Social Work, 16(2), 216-227. https://doi.org/10.1177/1468017315581564.

Pine, D. S. (2007). Research review: A neuroscience framework for pediatric anxiety disorders. Journal of Child Psychology and Psychiatry, 48(7), 631-648. https://doi.org/10.111 1/j.1469-7610.2007.01751.x.

Powell, B. J., Hausmann-Stabile, C., \& McMillen, J. C. (2013). Mental health clinicians' experiences of implementing evidence-based treatments. Journal of Evidence-Based Social Work, 10(5), 396409. https://doi.org/10.1080/15433714.2012.664062.

Raknes, S., Haaland, A. T., Haugland, B. S. M., Wergeland, G. J., Bjastad, J. F., Rogde, A. H., et al. (2015). Et gruppetilbud for ungdom som vil torre mer. [Groups for Adolescents Who Would Like to be Braver]. Bergen: RKBU Vest. 
Rapee, R. M., Lyneham, H. J., Schniering, C. A., Wuthrich, V., Abbott, M. A., Hudson, J. L., et al. (2006). The Cool Kids Child and Adolescent Anxiety Program Therapist Manual (School Version). Sydney: Macquire University, Cente for Emotional Health.

Rasmussen, L.-M. P., Patras, J., Neumer, S.-P., Adolfsen, F., Martinsen, K. D., Holen, S., et al. (2019). Facilitators and barriers to the implementation of EMOTION: An indicated intervention for young schoolchildren. Scandinavian Journal of Educational Research. https://doi.org/10.1080/00313831.2019.1596976.

Ringle, V. A., Read, K. L., Edmunds, J. M., Brodman, D. M., Kendall, P. C., Barg, F., et al. (2015). Barriers to and facilitators in the implementation of cognitive-behavioral therapy for youth anxiety in the community. Psychiatric Services, 66(9), 938-945. https:// doi.org/10.1176/appi.ps.201400134.

Schoenwald, S. K., Sheidow, A. J., \& Letourneau, E. J. (2004). Toward effective quality assurance in evidence-based practice: Links between expert consultation, therapist fidelity, and child outcomes. Journal of Clinical Child and Adolescent Psychology. https://doi.org/10.1207/s15374424jccp3301_10.

Spence, S. H. (1998). A measure of anxiety symptoms among children. Behaviour Research and Therapy, 36(5), 545-566. https:// doi.org/10.1016/S0005-7967(98)00034-5.

Stephan, S. H., \& Connors, E. H. (2013). School nurses' perceived prevalence and competence to address student mental health problems. Advances in School Mental Health Promotion, 6(3), 174-188. https://doi.org/10.1080/1754730x.2013.808889.

Tong, A., Sainsbury, P., \& Craig, J. (2007). Consolidated criteria for reporting qualitative research (COREQ): A 32-item checklist for interviews and focus groups. International Journal for Quality in Health Care, 19(6), 349-357. https://doi.org/10.1093/intqhe/ mzm042.

Waite, P., \& Creswell, C. (2014). Children and adolescents referred for treatment of anxiety disorders: Differences in clinical characteristics. Journal of Affective Disorders, 167, 326-332. https://doi. org/10.1016/j.jad.2014.06.028.

Werner-Seidler, A., Perry, Y., Calear, A. L., Newby, J. M., \& Christensen, H. (2017). School-based depression and anxiety prevention programs for young people: A systematic review and metaanalysis. Clinical Psychology Review, 51, 30-47. https://doi. org/10.1016/j.cpr.2016.10.005.

Wittchen, H. U., Beesdo, K., Bittner, A., \& Goodwin, R. D. (2003). Depressive episodes-evidence for a causal role of primary anxiety disorders? European Psychiatry, 18(8), 384-393.

Youngstrom, E., Loeber, R., \& Stouthamer-Loeber, M. (2000). Patterns and correlates of agreement between parent, teacher, and male adolescent ratings of externalizing and internalizing problems. Journal of Consulting and Clinical Psychology, 68(6), 10381050. https://doi.org/10.1037//0022-006x.68.6.1038.

Publisher's Note Springer Nature remains neutral with regard to jurisdictional claims in published maps and institutional affiliations. 